\title{
Conversas entre psicologia e educação em práticas de moralização, normalização e legalistas
}

\author{
Flávia Cristina Silveira Lemos ${ }^{1}$, https://orcid.org/0000-0002-6601-0653 \\ Dolores Galindo², https://orcid.org/0000-0003-2071-3967 \\ Maria Livia do Nascimento ${ }^{3}$, https://orcid.org/0000-0002-6451-484x \\ Luanna Tomaz ${ }^{4}$, https://orcid.org/0000-0002-8385-8859
}

\begin{abstract}
Resumo
Este artigo aborda um trabalho de pesquisa bibliográfica de alguns conceitos de Michel Foucault para pensarmos a democracia na relação com educação, a psicologia política e a governamentalidade. Para tanto, analisa práticas de dominação, violência e ética, na subjetividade e na estética da existência na produção da liberdade. Assim, são utilizados acontecimentos históricos para a problematização do presente em que vivemos, entre eles alguns da chamada Nova República brasileira e dos contextos de mundialização, de medicalização, de empreendimentos da vida, da cidadania menorizada e valorizada pela exceção jurídica e médico-psicológica. Trazer a coragem da verdade para a ética, a estética e a política nos ajuda a analisar questões que nos inquietam, nos atravessam, nos movem historicamente a problematizar determinados processos de subjetivação da atualidade.
\end{abstract}

Palavras-chave: Democracia; psicologia; educação.

\section{Conversations between psychology and education in practices of moralization, standardization, and legalists}

\begin{abstract}
This article approaches a bibliographical research of some concepts of Michel Foucault to think about democracy in relation to education, political psychology, and governmentality. To do so, it analyzes practices of domination, violence, and ethics, in the subjectivity and aesthetics of existence in the production of freedom. Thus, historical events are used for the problematization of the present in which we live, among them some of the so-called New Brazilian Republic and the contexts of globalization, medicalization, life endeavors, and citizenship that has been valorized by the legal and medical-psychological exception. Bringing the courage of truth to ethics, aesthetics, and politics helps us analyze issues that trouble us, cross us, move us historically to problematize certain processes of subjectivity today.
\end{abstract}

Keywords: Democracy; psychology; education.

\section{Charlas entre Psicologia y Educación en prácticas de moralización, normalización y legalistas}

\section{Resumen}

En este artículo aborda un estudio de investigación bibliográfica de algunos conceptos de Michel Foucault para pensar la democracia en la relación con educación, la psicología política y la mentalidad gubernamental. Para tanto, se analiza prácticas de dominación, violencia y ética, en la subjetividad y en la estética de la existencia en la producción de la libertad. Así, se ha utilizado hechos históricos para la problematización del presente en que vivimos, entre ellos algunos de la llamada Nueva República brasileña y de los contextos de mundialización, de medicalización, de emprendimientos de la vida, de la ciudadanía minimizada y valorada por la excepción jurídica y médico-psicológica. Traer el coraje de la verdad a la ética, la estética y la política nos ayuda a analizar cuestiones que nos inquietan, nos atraviesan, nos mueven históricamente a problematizar determinados procesos de subjetivación en la actualidad.

Palabras clave: Democracia; psicología; educación.

1 Universidade Federal do Pará, Faculdade de Psicologia - Belém, PA, Brasil.

2 Universidade Federal do Mato Grosso, Programa de pós-graduação em estudos da cultura contemporânea - Cuiabá, MT, Brasil

3 Universidade Federal Fluminense, Instituto de Ciências Humanas e Filosofia - Niterói, RJ, Brasil

4 Universidade Federal do Pará, Faculdade de Direito - Belém, PA, Brasil 


\section{Introdução}

Este artigo tem por objetivo pensar alguns operadores conceituais, a partir do trabalho de Michel Foucault, para realizar uma discussão a respeito da democracia, da educação e do neoliberalismo, em uma perspectiva da psicologia política. Para tanto, trazemos alguns analisadores da democracia brasileira durante a chamada Nova República e problematizamos os efeitos dos mesmos, em uma história do presente. Pensar a crítica ao legalismo do presente, por meio da defesa da sociedade, na busca de segurança e pela exaltação da democracia neoliberal suscita inquietações diversas e nos faz problematizar processos de subjetivação da atualidade em que vivemos.

Traçar a crítica aos totalitarismos e defender a democracia parece não ser suficiente para nos livrar dos fascismos dos regimes ditatoriais e de campos de concentração e/ou de seus resquícios. Nesse plano, a ética associada à política, não apenas representativa e participativa da soberania jurídica e da figura do Estado de Direito, pode ser uma via possível de produção da liberdade pela coragem e pelos seus riscos, frente às lógicas do mercado avassalador das subjetividades empresariais que abrem mão de qualquer cuidado, problematizado em nome da segurança e do lucro.

Nas eleições brasileiras do ano de 2014, para presidente da República, de deputados, senadores e governadores, acompanhamos um conjunto de situações estarrecedoras de ausência de ética e de atualizações fascistas. Ódios e ressentimentos vieram à tona e ganharam materialidade em estigmas, preconceitos, discriminações, violências e disputas legais e ilegais. Analisar esses acontecimentos nos auxilia a interrogar o que fazemos de nós e com os outros, no tempo em que vivemos.

\section{Soberania jurídica, dominação, disciplina e biopolítica: efeitos na democracia}

Na conferência O sujeito e o poder, na Universidade de Berkeley, Foucault (1995) afirma que, na governamentalidade, ou seja, nos governos das condutas, há hoje a articulação de processos de dominação, violência e poder. Essas práticas seriam diferentes, contudo, correlacionadas. Essa conferência nos auxilia a pensar as relações entre as governamentalidades, nas democracias atuais, e como suas articulações forjam ressonâncias na regulação dos corpos e na manutenção de cristalizações de modos de dominação política, social e econômica, ou ainda, das mobilidades de resistências e poderes dinâmicos, em exercícios cotidianos de incitação e produção de realidades, de saberes e de subjetividades.

Diferenciar poder de violência traz uma novidade em termos de análise, já que era muito comum um amálgama entre essas duas práticas, como se as mesmas fossem sinônimas. Para Foucault (1979; 1988), há, tradicionalmente, uma análise de poder por meio da soberania jurídica, da lei como ferramenta para minimizar opressões e impedir abu- sos de poder. O direito conferiria legitimidade representativa e participativa para o exercício de práticas de governo das condutas, em figuras como o Estado e a sociedade civil.

A filosofia política e o direito público possibilitaram a formação de racionalidades jurídicas para definir poder como localização, como direito, legitimidade, representatividade, mediação e repressão legal. Todavia, os poderes podem operar por um exercício bem mais móvel e dinâmico, quando se relacionam com saberes diversos, em jogos de força heterogêneos e regimes de verdade mutantes, nos diagramas provisórios (Foucault, 1979). As táticas de poder disciplinar, biopolíticas e de segurança são modos de esses poderes e saberes móveis atuarem, em conjunto, pelas normas sociais prescritas por práticas sociais e culturais que se dirigem aos corpos individuais e coletivos, mutuamente.

Em História da Sexualidade I, Foucault (1988) define diferenças entre lei e norma, mas aponta as relações entre ambas. Para ele, a analítica do poder pressupõe a problematização das normas, de saberes que sustentam prescrições de viver, de sentir, de pensar e de agir, mas que são constituídas o tempo todo em negociações, com resistências, divergindo da proibição legal, pois as normas prescrevem enquanto as leis proíbem. Por isso, lei e norma são diversas e a repressão normatizadora se diferencia da incitação política e social das normalizações.

É possível punir pelas normas no campo da disciplina; já a punição pela lei implica penalidades e julgamentos pela ruptura denominada infração e não apenas pelo desvio das normas sociais. Punir disciplinarmente é uma prática de poder disciplinar e traz castigos, por meio das sanções normalizadoras. Punir legalmente já significa a utilização de um código penal e a execução de uma política criminal instituída por penas de prisão, por penas alternativas e julgamentos baseados no Poder Judiciário.

No caso das normas, as avaliações remetem aos exames de verdade e a uma política de controle social disciplinar, baseada na vigilância hierárquica e na avaliação em verdade dos sujeitos desviantes sociais. Nesse segundo caso, falamos de instituições parajudiciárias, julgando a quebra das normas e punindo por meio de exercícios repetidos de inclusão social e de docilização acentuada dos corpos para aumento da produção (Foucault, 1996, 1999).

Assim, ao pensar a Revolução Francesa, Foucault (1999a) afirma que, esta inventou as liberdades e também as disciplinas como tecnologias de poder-saber e subjetivação. Ou seja, a criação da liberdade jurídica, no liberalismo político e econômico, trouxe de forma imanente o adestramento normalizante dos corpos, fabricando o modo indivíduo de existência como efeito das práticas de poder disciplinares, amparadas em saberes. Equipamentos, tais como as fábricas, as escolas, as prisões, os conventos, as famílias, os hospitais e os exércitos, teriam o objetivo de disciplinar os corpos para torná-los úteis e dóceis. As táticas disciplinares seriam o controle no espaço e no tempo, o exame, a vigilância e a sanção normalizadora.

As leis poderiam ser interligadas às normas em algum momento e, por isso, Foucault (1979) alertava para 
a relação entre soberania jurídica e disciplina pelo poder, pelo direito e pela verdade. A pesquisa da história de vida para punir legalmente e para estabelecer penas, nos casos de circunstâncias atenuantes, por exemplo, poderia entrar em conjugação política e traçar articulações entre normas e leis. Todavia, a lei teria um impacto menos contínuo de controle das condutas do que as disciplinas normalizadoras, de acordo com Foucault (1999a). Vigiar em meio aberto, corrigir sem prender em asilos isolados e poder aumentar a produtividade simultaneamente à docilização política era uma preocupação no liberalismo emergente. As liberdades nascentes ocorreriam no campo da disciplina dos corpos, permanentemente, ao ponto de cada um se imaginar sendo vigiado antes de fazer qualquer coisa, mesmo que de fato não o fosse.

O panoptismo era essa máquina de subjetivação em que os corpos se viam como olhados o tempo todo e, então, decidissem obedecer às regras de conduta sem que tivessem a obrigação legal e sem que fossem punidos por penas duras. Se era comum punir excluindo, anteriormente, com o envio para asilos e casas de correção, agora, com as disciplinas, seria possível punir incluindo, pela norma e pelo controle contínuo dos corpos. A efetividade disciplinar era maior e mais barata que a lenta, irregular e cara justiça penal. Essa nova sociedade emerge por volta do final do século XVII e início do século XVIII. Assim, nas democracias que acabavam de aparecer, com a emergência dos Estados Modernos, o utilitarismo liberal se tornava um estilo de vida a ser adotado pela disciplina regular e contínua da minúcia dos comportamentos vigiados o tempo todo e entre os próprios corpos, nas relações microfísicas. Ou seja, cada um vigiaria o outro sem custo econômico, necessariamente, pois, na família, na amizade, na vizinhança, haveria uma relação baseada no controle social pela cultura, pela sociabilidade e pelo uso dos saberes (Foucault, 1979, 1988, 1999a).

Mas a resistência seria a brecha da liberdade de cada um diferir e não aceitar a sujeição normalizadora. Essa possibilidade abre o campo ético do que Foucault denominou, posteriormente, agonística (Foucault, 2010a). A relação de poder só existe na liberdade; não há como resistir à escravidão e é muito difícil fazê-lo frente às situações de dominação intensas (Foucault, 1995). Se as democracias constitucionais forjaram as liberdades jurídicas, pautadas nas leis, podemos pensar liberdades fora da esfera legalista, as que se materializam no plano ético das governamentalidades. Ora, em sociedades de dominação e de regimes ditatoriais e totalitários, é interessante garantir as liberdades legalmente; contudo, o que afirmamos é o fato de que a liberdade não é produzida apenas pela legislação e nem garantida somente pela mesma (Foucault, 2010b).

Em democracias, é possível ter ampla liberdade de expressão constitucional e pouca possibilidade de falar efetivamente. Um exemplo brasileiro é a prisão arbitrária de pessoas que protestam nas ruas; é a tentativa de calar estudantes com diagnósticos e registros em livros de ocorrências escolares; é o isolamento no trabalho de trabalhadores que se manifestam em face da exploração; é a morte de jornalistas que fizeram denúncias; é o medo de falar e ser classificado como inimigo social, entre tantas outras figuras que assinalam que a coragem da verdade é um risco nas democracias, conforme Foucault destaca, em O governo de si e dos outros (Foucault, 2010a) e em A coragem da verdade (Foucault, 2010b), ao analisar a restrição da palavra franca nas democracias.

O tipo de fala aceito com facilidade pelo exercício da liberdade de expressão legalmente instituída é a persuasão e a hipocrisia da bajulação. Falar fora desse regramento é submeter-se ao risco de ser morto, de ser preso, de sofrer ostracismos, de ser impedido de diversas formas de ascensão no trabalho e de acesso a lugares institucionais diversos. Assim, Foucault (2010a, 2010b) está chamando nossa atenção para a relação entre ética, produção de liberdade, estilo de existência e política. Enganam-se aqueles que acreditam na judicialização exacerbada da vida, pelo aumento infinito de leis e penas correlatas para tornar a sociedade mais ética e livre, linearmente.

De fato, o investimento na lei e a proliferação das leis que vemos no contemporâneo somam-se a outras forças que reafirmam práticas judiciárias de particularização, de fragmentação, porque, com a lei, se perde de vista a referência à luta política, social e popular, afirmando uma tradição jurídica legalista forte, a qual faz com que a lei tenha um peso enorme, ao atuar por ameaça àqueles que a transgridam.

A emergência da gestão da vida como valor na história, em uma entrada política do corpo da população como espécie biológica no fazer viver e deixar morrer, acarreta o nascimento da biopolítica, a partir da segunda metade do século XIX. No curso Em defesa da sociedade (Foucault, 1999), há uma definição da biopolítica como prática de governo da população em nome da vida, da expansão da saúde, da segurança e da paz. Defender a sociedade se torna um mote para matar aqueles que ameaçam a ordem. A lógica é proteger o Estado, de modo que, assim defendido, ele possa cumprir sua função de proteger a sociedade. Pelo Estado de Direito, é forjada a racionalidade da lei e da ordem, o que torna alguns, alvo de merecimento da vida e outros inimigos sociais, na visão de cidadania relacionada ao mérito e à moral, e à avaliação de diferenças pela hierarquia de modelos baseados em saberes da ciência, os quais classificam modos de ser como mais e menos normais.

A moral está no plano da dominação, é a visão de que existe algo como cidadãos de bem e os não cidadãos, não humanos no plano moral. A figura jurídica do cidadão é associada aos valores morais. A cidadania se torna resultado de merecimento de alguém que obedece a um caminho supostamente correto, dito de bem. Essa é uma dimensão da dominação: o campo moral. Foucault $(1979,1995)$ ressalta que a disciplina incorporou elementos da moral, atualizados pelos saberes da ciência, dando novos contornos para as práticas de dominação anteriores. Ou seja, valores de cunho moral ganharam justificativas científicas e chancelas de suposta neutralidade, todavia, com a incorporação de outros elementos culturais, sociais, econômicos e históricos. 
O que significa que operou-se uma descontinuidade entre moral e normas.

Várias práticas têm materializado a violência e a dominação socioeconômica, suspendendo a lei para que a exceção se torne a regra, em nome da segurança. Basta pensar na prisão de Guantánamo e no aprisionamento arbitrário de supostos suspeitos de terrorismos, sem qualquer tipo de julgamento, à mercê de torturas, em um ato de extrema exceção à democracia (Bauman, 2005). Outro exemplo é o ataque aos civis de países do Oriente pelos EUA, utilizando drones, em nome da defesa da democracia mundial. Em termos do aumento massivo do encarceramento e do acirramento das punições legais, há uma intensificação de racionalidades penais, tais como: a proposta de castração química como punição legal para autores de violência sexual; a pena capital para os que cometeram homicídios; prisão perpétua para os que realizaram tráfico de drogas e/ ou se envolveram em situações de roubos sequenciais à mão armada, seguidos de morte.

Essas práticas descritas no presente tópico podem sinalizar o uso da violência por vários Estados, em nome da segurança e da paz mundial, paradoxalmente aos direitos garantidos legalmente nas constituições e nos princípios humanitários das cartas internacionais de direitos da Organização das Nações Unidas (Wieviorka, 2008).

\section{Brasil, democracia e subjetividades atravessadas pelo medo e terror}

Em 1985, é iniciada a abertura política brasileira e a transição para a chamada redemocratização e Nova República brasileira. Movimentos sociais lutam pelas eleições diretas e pela criação de uma Assembleia Constituinte, após anos de silêncio e de violência ditatorial, durante o Regime Civil-Militar. A tentativa desses movimentos era superar autoritarismos, violações de direitos, ausência de liberdade de expressão, torturas, desaparecimentos políticos, exílios, mortes e perda de direitos políticos, civis, sociais e culturais (Carvalho, 2001; Reis, 2014).

A derrota se dá na busca das eleições diretas, pois a abertura política como estratégia da chamada democratização lenta e gradual da Ditadura foi fruto de um acordo que preservou ranços do militarismo e garantiu que a ruptura fosse pouco expressiva, frente ao que buscavam os movimentos sociais. Apenas em 1990, assume o primeiro presidente eleito diretamente na Nova República, Fernando Collor de Mello. Em 1988, foi aprovada a Constituição denominada Cidadã. A Constituição foi um marco, apesar de a lei não ser o único elemento a alterar os quadros: culturais, políticos, sociais e subjetivos (Reis, 2014).

Ter uma lei possibilita conquistas para as lutas cotidianas, mas, no plano da normalização social, outros dispositivos são relevantes para o que Foucault (1979) chamou de insurreição de saberes assujeitados dos saberes para as resistências políticas, diante dos processos de controle social disciplinar. Há um plano ético e estético da existência que vai além, não ocorre apenas na esfera jurídica e podemos apostar nele, também. Isso não quer dizer que iremos desvalorizar a Constituição de 1988 e as leis, porém, que não colocaremos todas nossas apostas nelas, apenas para democratizar mais um sistema político, democratizar relações e subjetividades, ou para produzir quebras de dominações históricas e de moralizações longínquas.

Paradoxos variados foram instalados e trouxeram preocupações analíticas em diversas áreas de estudo e no plano das representações da soberania jurídica, na esfera dos movimentos sociais e de organizações multilaterais da diplomacia da Organização das Nações Unidas (ONU). Contudo, as organizações internacionais puderam compor e intervir, cobrando do Brasil, de modo contundente, o cumprimento de pactos de direitos após o término da Ditadura Civil-Militar. Essa possibilidade implicou pressões e tensões instaladas, que foram positivas para as lutas sociais; em um país, como o Brasil, ainda muito marcado pela cultura política autoritária.

A polícia brasileira permaneceu militarizada, violações de direitos ainda se mantiveram em outros aspectos das sociabilidades de dominações, tais como sociais, econômicas, morais, religiosas e de gênero, as quais ganharam novas incidências e discriminações de raça/etnia e de orientação sexual, surgindo de forma mais incisiva ainda. Vale destacar quando Deleuze (1992) declara que a sociedade atual se torna cada vez mais gestão de marketing empresarial, em contextos democráticos, paralelamente ao acirramento de controles intensos rápidos e de difícil resistência. Ele aponta os paradoxos e fracassos das reformas infindáveis da escola, da fábrica, da família e de outras instituições e dos aparatos de governo das condutas.

As relações estariam cada vez mais pautadas na capitalização e no empresariamentosem ética, em que marcas e estilos de vida se tornaram kits de subjetividades maximizadoras da exponencial concentração de renda e de formação de guetos de miséria no interior dos países democráticos e ditos desenvolvidos, do retorno de fascismos mais arcaicos como processo de subjetivação e com efeitos de extermínio massivos (Deleuze \& Guattari, 2010; Hobsbawm, 2007).

Em Segurança, território e população, Foucault (2008b) declara que o poder pastoral era o governo do rebanho para a salvação das almas, da Antiguidade até a Idade Média. Esse poder pastoral foi transformado em governo das condutas, pela moralização, pelo poder disciplinar, pela biopolítica e, posteriormente, pelo dispositivo de segurança, na emergência do Estado governamentalizado e do liberalismo econômico e político como condução das condutas da população.

Entre os dispositivos de segurança, estão: a concorrência entre os países, a circulação geográfica, o mercado internacional, a diplomacia, a polícia médica, o surgimento de forças militares profissionalizadas, a visão da democracia como negociação de interesses sociais e econômicos, a judicialização extrema das relações sociais, o empresariamento de si e dos outros, nos mais diversos espaços e 
modos de vida, e a redução do financiamento estatal das políticas sociais em prol do aumento das políticas de segurança para alguns grupos frente a outros (Foucault, 2008b).

O empreendedorismo, no Estado Democrático de Direito e no neoliberalismo, se materializa pela relação entre a lei, a norma e a moral, articulando liberdade e segurança. A questão crucial do liberalismo é a da liberdade com segurança (Foucault, 2008b). O liberalismo se tornou um estilo de vida e colocou o sujeito de direitos articulados aos sujeitos econômicos, a partir do eixo segurança e cálculo de custo e benefício. Cada um passa a ser visto como capital, como empresário de si e dos outros, para gerar renda; os que não gerarem e quebrarem o pacto social sofrerão danos e punições na esfera jurídica, normalizadora e moralizadora.

As democracias capitalistas neoliberais funcionam em Estados de Direito nos quais o problema da circulação ganha relevância no mercado. A defesa poderá ser realizada, impedindo a circulação de alguns, para que outros tenham acessibilidade. Bauman (1999) destaca como as fronteiras são fechadas entre Estados, regiões, municípios e entre continentes, para determinados grupos, classificados enquanto refugos da sociedade neoliberal. Nesse aspecto, a democracia não é apenas a ausência ou presença de certa maneira de realizar a soberania jurídica, mas corresponde a práticas sociais, culturais, econômicas, históricas e de produção de subjetividades. A moral pode ser questionada nas democracias e, em algum momento, ser convocada nos processos eleitorais, nos tribunais, na oferta de saúde e gestão da vida.

As eleições de 2014, no Brasil, trouxeram situações as mais bizarras, em termos de ausência de ética, de ilegalidade, de legalismos, de criminalizações, de denúncias morais, de disputas regionais, de desqualificações de gênero e de classe, de encomendas de perdas de direitos e pedidos de retorno dos militares à gestão do Estado brasileiro, por um novo golpe militar, para a surpresa muitos e, em especial, para os que lutaram pela saída da Ditadura Civil-Militar.

Racismos e violências reapareceram de forma gritante, com trocas de ofensas, ataques aos movimentos sociais nas ruas, depredações diversas e declarações de ódio, nas redes sociais. Esses racismos estavam aí, bem à frente dos nossos olhos, e não conseguíamos vê-los? A que ponto a sedução democrática nos impediu de enxergar racismos tão vociferantes? Ficamos encantados com a abstração da lei e perdemos o escopo das lutas cotidianas, no plano ético, estético e político de nossas existências? Quais rupturas fomos capazes de efetuar, de fato, em face dos autoritarismos e dominações?

Interroguemos sobre quais processos de subjetivação ocorreram, para que possamos analisar de que modo forças autoritárias e de dominação foram atualizadas pelas lógicas morais, normalizantes e legais, sustentando encomendas de violência e de defesa da manutenção de oligarquias políticas, de disputas de classe, de orientação sexual e de gênero, de apartheids regionais e segregações políticas. Diante de tal quadro, voltemos às questões que trouxemos como operadores conceituais, no artigo, e pensemos até que ponto a ética ganhou espaço nas democracias, em especial, na brasileira, e de que maneira o fascismo pode andar lado a lado a regimes políticos não totalitários. A ética foi relegada a um segundo plano, em nome da segurança, para os que defendem o utilitarismo da governabilidade, fundamentada em mecanismos de exceção. A lei pode guiar atos políticos e ir para debaixo do tapete, pelo uso de normas para assegurar proteção a alguns grupos frente a outros, na seletividade penal e/ou na escolha de quem vai viver e de quem vai morrer.

O deixar morrer e matar em nome da vida implica pensar o quanto um dispositivo de segurança pressupõe o monopólio estatal da violência com as polícias militarizadas, os exércitos profissionalizados, a diplomacia mediadora de tensões e guerras, a definição de penalidades para alguns grupos, inclusive a pena de prisão perpétua e a pena capital (Foucault, 2008a). Ao problematizar a biopolítica funcionando no dispositivo de segurança, Foucault (1988, 1999b) enfatiza que nunca se matou e se deixou tanto morrer quanto nas sociedades que exaltaram a vida e a democracia, como valores supremos.

Guattari (1985), no livro Revolução Molecular, ressalta que os microfascismos podem atravessar e se atualizar em todos nós, ou seja, não são práticas apenas de Estados Ditatoriais e autoritários, apesar de neles ganharem maior incidência e regularidade, configurando uma política de um Estado de terror levada ao paroxismo. Hobsbawm (2007) sinaliza que, na sociedade contemporânea, os dispositivos militares foram deslocados mais frequentemente das guerras mundiais para a segurança de civis, no interior dos Estados de Direito. Armas voltadas anteriormente contra outros países foram dirigidas para os denominados inimigos internos, em nome da pacificação de favelas, da dispersão de revoltas populares, a fim de aumentar a vigilância das cidades em períodos de eventos esportivos e políticos.

No Brasil, isso ocorreu nos Jogos Panamericanos, na Copa das Confederações, na Copa do Mundo e está previsto para as Olimpíadas. Também foi amplamente utilizado para operar cercos às comunidades periféricas dos grandes centros urbanos e para policiar fronteiras variadas, na chamada guerra às drogas. A produção do inimigo interno é permanente e este pode ser qualquer um de nós, desde que entremos no espectro do julgamento moral dos que se consideram puros, do racismo de Estado e de sociedade, na biopolítica, da disciplina normalizadora e do dispositivo de segurança que aciona a violência e o cárcere contra os que ousam interrogar, pensar, ter a coragem de revoltar-se. A criação da Força Tarefa Nacional foi uma iniciativa que articulou as Forças Armadas com as polícias militares, federais e civis, em operações em diferentes situações e lugares do Brasil considerados críticos, na avaliação de uma política de gestão de riscos/perigos, na produção de uma política securitária.

Essa iniciativa ganhou intensificação na Copa do Mundo, em 2014, e a militarização do cotidiano com a Força Nacional fez-se igualmente intensiva, nas regiões dos grandes projetos de infraestrutura desenvolvimentistas, em função das resistências de movimentos sociais diante das violações de direitos ocorridas em praticamente todas as 
obras do PAC. A perspectiva da ordem e lei, presente no Estado Democrático de Direito neoliberal, aciona militarizações para gerir a circulação com segurança para empreendimentos e consumos, geração de renda e reformas variadas, as quais promovam cada vez mais a limpeza social, em nome da pacificação armada e higienista.

Muitas pessoas em situação de rua têm sido retiradas permanentemente dos centros das cidades e recolhidas em lugares de isolamento segregativo, como estratégia higienista dos espaços de circulação. No Brasil, a criação dos chamados empreendimentos da construção civil, das reformas para ampliação de malhas viárias e dos metrôs tem lançado mão das remoções forçadas e implicado no envio de parcelas significativas de contingentes pobres para as periferias urbanas, em nome das "reciclagens" biopolíticas e disciplinas dos espaços e dos corpos. A violência na retirada desses grupos tem sido permanente, usando a força policial. Após reformados e alterados em seu desenho, esses bairros se tornam caríssimos e são alvo de especulação imobiliária perversa, impedindo a presença de quem anteriormente os habitava e por eles transitava.

A disciplina entrava na democracia pela noção de que a educação formaria cidadãos, que a medicina higienista os forjaria pelos aparatos de saúde e que o trabalho criaria cidadania pelo contrato liberal possibilitando consumo, salário e dignidade. Essas e outras maneiras, que poderíamos citar, de práticas disciplinadoras dos corpos trazem uma dimensão da democracia chamada de autonomia, o que significaria a produção do modo indivíduo de ser como efeito do poder disciplinar.

Na biopolítica, especificamente, o racismo é articulado ao Estado de Direito pela economia política e pela administração fundamentada em cálculos estatísticos e na medicalização da população. A cidadania jurídica é associada à visão de normalidade e, diante da falta de razão, da presença da infância no adulto, classificada como psicopatologia, entra em cena a retirada de direitos por medidas de segurança.

Portanto, tem-se a perda da cidadania, pelo diagnóstico de peritos médicos com seus pareceres, os quais subsidiam decisões de juízes sob a tutela e até mesmo para encaminhamentos às internações compulsórias de usuários de drogas e aos manicômios judiciários, para que cumpram os nomeados tratamentos penas, por exemplo. Tais ações são muito comuns, no mundo contemporâneo, e, igualmente, na atualidade brasileira.

O racismo ganhou um aparato de defesa da sociedade: contra os anormais, contra os não educados e contra os imorais. Por conseguinte, contra aqueles que são avaliados como inimigos sociais, por estarem fora do plano da cidadania jurídica, sendo classificados como um corpo espécie biológica desumanizada. Nesse campo, instala-se o racismo, a noção de humano e sua relação com a defesa social. Paradoxo da biopolítica: fazer viver os que são definidos como cidadãos e deixar morrer ou até mesmo matar os considerados não cidadãos (Foucault, 1999b).

A frase muito comum entre policiais militares e civis brasileiros, de que "bandido bom é bandido morto", poderia se enquadrar nessa visão moral e fora do quadro legal. Ou, ainda, a noção de que a exceção pode ser usada para governabilidade em nome da defesa da sociedade é outro exemplo de quebra da democracia, de sorte a assegurar a alguns grupos vistos como merecedores da vida, frente a outros, tachados de inimigos não merecedores de proteção. Nessa direção, é um dos potentes analisadores da atualidade brasileira e de outros países o fato de que alguns morrem porque merecem, ou que não recebem os cuidados devidamente estipulados na Constituição brasileira de 1988, por meio do atendimento digno das políticas públicas. Profissionais alegam o não cuidado ou a atenção realizada precariamente a esses grupos como uma questão justificada pela visão de merecimento moral, o que configura violação de direitos e pode chegar a ganhar dimensão de violência estatal. É muito comum a negativa de profissionais das políticas de educação e saúde a atender adolescentes que cometeram atos infracionais e usuários de drogas, por motivos de avalição moral dos atos desses segmentos da população.

O medo é um dos mecanismos bastante acionados para fazer essas reformas urbanas, juntamente com as práticas de violência e de violação de direitos. A constituição de inseguranças é forjada cotidianamente, nas grandes mídias e em discursos de políticos que representam o povo em cargos públicos, sobretudo os dos altos escalões do Estado. Todavia, não somos geridos pelo medo e pelo terror que envolve a gestão do mesmo apenas pelo Estado, pois as grandes corporações multinacionais operam essa tecnologia de modo bem mais intensivo que os Estados nacionais, a fim de fazer valer seus interesses econômicos.

Por isso, a governamentalidade pressupõe mais do que a figura abstrata do Estado e significa uma análise da multiplicidade de forças que o constituem e que operam com ele, por meio dele e sem lançar mão das estratégias estatizantes da vida e dos corpos. O Estado é apenas efeito de entrecruzamentos das forças de soberania com as da disciplina, da biopolítica, da segurança e da moralização, no Complexo Tutelar. Foucault (2008b) problematiza que o Estado se tornou governamentalizado, na atualidade, mas que os governos das condutas ocorrem não apenas por ele. Dessa maneira, inúmeras maneiras de gerir e diferentes modos de fazê-lo podem entrar em composição para o empresariamento de si e dos outros, tais como a moral, a norma, a lei, a gestão de riscos e a tutela as democracias neoliberais de hoje.

Em Segurança, território e população, Foucault (2008b) aponta a realização dos negócios no espaço com seguridade e como as cidades vão ganhando uma lógica de organização que beira os acampamentos militares, para favorecer a circulação de bens, pessoas, conhecimentos, normas e equipamentos diversos. Abrir conexões entre os espaços para ampliar o empresariamento da vida é um vetor de forças neoliberais cada vez mais incisivas e esmagadoras das esferas coletivas e das redes de solidariedade, pois afasta comunidades e inibe as resistências em nome do desenvolvimento e do aumento da geração de renda (Foucault, 2008b). Concluindo, a economia política ganha mais 
importância que os direitos, nessa racionalidade, de maneira que, para efetuar esse projeto de sociedade, os racismos, a moral, as normas e a tutela são usadas para gerenciar populações, para tentar docilizar e moralizar os corpos.

\section{Considerações finais}

O chamado Estado democrático de direito é uma conquista para os países que saíram das ditaduras, contudo, não é suficiente para nos tornar éticos. A violência, a violação de direitos e as desigualdades socioeconômicas, apesar de diminuídas, ainda estão presentes regularmente como modo de sociabilidade, efetuada pelo próprio Estado, seja legitimada pela noção de monopólio estatal, seja fora dessa visão de legitimidade jurídica.

Chauí (1985) assinala que o conformismo e os conservadorismos de sociabilidades autoritárias ainda foram preservados e atualizados, durante a redemocratização brasileira. A despeito da importância da abertura e do estabelecimento de um quadro jurídico político democrático, baseado em leis consideradas avançadas no plano constitucional e de garantismo legal, ainda prevalecem clientelismos, nepotismos, coronelismos e violências policiais, lógicas de direitos como favor, sendo ampliadas as desigualdades sociais e econômicas na entrada do Brasil no cenário de internacionalização neoliberal.

Os direitos políticos, civis e sociais foram criados com muita luta, porém, outras lutas se fazem importantes, para produzir liberdade, já que a mesma não é fruto apenas de decretos e não se restringe ao aparato de governamentalidade da soberania das democracias participativas e representativas. A analítica do poder pensada por Foucault (1988) traz um aspecto interessante para as lutas do presente de ampliação da ética, da estética e da política, porque promove a tensão e a política como desentendimento e não como consenso à força, ou pela dominação ou ainda pela lei.

Romper com o campo moral de que há uma condição humana tal qual uma natureza e uma essência poderá auxiliar na busca de uma estilística da existência que faça a política por espaços outros, para além do homem e do humano e para além das morais fascistas. O que é bom para um não necessariamente o é para os outros e, nessa avaliação, consiste a dimensão ética. Quando querem impor o que supostamente é bom para alguns para todos e para o outro, temos a moral e não a ética em jogo.

Assim, após essas análises, tentamos apostar em práticas éticas que afirmam o reconhecimento das diferenças, em uma estética da existência comprometida com processos permanentes de invenção da vida e em experimentações políticas que sustentem nossos compromissos e os riscos de práticas implicadas. A resistência ao legalismo, à criminalização, à medicalização, à judicialização, ao empresariamento da vida e à dominação pode ser materializada pela arquitetura dos dispositivos de produção de liberdade e de afirmação de potências de encontros em que o ódio e os ressentimentos possam dar espaço para as estilísticas de existências com a coragem da verdade e a agonística do pensar e para que seja possível o exercício de subjetividades que visem a romper com os fascismos cotidianos.

\section{Referências}

Bauman, Z. (1999). Globalização: as consequências humanas. Rio de Janeiro: Zahar.

Bauman, Z. (2005). Vidas desperdiçadas. Rio de Janeiro: Zahar, 2005.

Carvalho J.M. (2001). Cidadania no Brasil: o longo caminho. Rio de Janeiro: Civilização Brasileira.

Chauí, M. (1985). Conformismos e resistências. São Paulo: Brasiliense.

Deleuze, G. (1992). Conversações. Rio de Janeiro: Editora 34.

Deleuze, G.; Guattari, F. (2010). O que é a filosofia? (3a. ed.). Rio de Janeiro: Editora 34

Foucault, M. (1979). Microfísica do poder. Petrópolis/RJ: Vozes, 1979.

Foucault, M. (1988). História da Sexualidade I: a vontade de saber. Rio de Janeiro: Graal.

Foucault, M. (1995). "O sujeito e o poder". In: Dreyfus, H \& Habinow, P. Michel Foucault: uma trajetória filosófica. Rio de Janeiro: Forense.

Foucault, M. (1996). A verdade e as formas jurídicas. Rio de Janeiro: Nau.

Foucault, M. (1999). Em Defesa da Sociedade. São Paulo: Martins Fontes.

Foucault, M. (2008a). O Nascimento da Biopolítica. São Paulo: Martins Fontes.

Foucault, M. (2008b). Segurança, território e população. São Paulo: Martins Fontes.

Foucault, M. (2010a). O governo de si e dos outros. São Paulo: Martins Fontes.

Foucault, M. (1985). A coragem da verdade. São Paulo: Martins Fontes.

Guattari, F. (1985). Revolução molecular. São Paulo: Brasiliense.

Hobsbawm, E. J. (2007). Globalização, democracia e terrorismo. São Paulo: Companhia das Letras.

Reis, D.A. (2014). Ditadura e democracia no Brasil. Rio de Janeiro: Zahar. 
Wieviorka, M. (2008). Em que mundo viveremos? São Paulo:

Perspectiva.

Recebido em: 20/06/2016

Aprovado em: 30/01/2017

\section{Sobre as autoras}

Flávia Cristina Silveira Lemos (flavazevedo@hotmail.com).

Profa. adjunta IV de Psicologia Social/UFPA. Bolsista de Produtividade CNPQ-PQ2. Psicóloga/UNESP. Mestre em Psicologia Social/UNESP. Doutora em História Cultural/UNESP. Pós-doutora em Processos de subjetivação/UFF. Belém -PA.

https://orcid.org/0000-0002-6601-0653

Dolores Galindo (dolorescristinasilveiralemos@gmail.com)

Psicóloga/UFPE, Mestre e Doutora em psicologia social/PUC-SP. Professora no programa de pós-graduação em estudos da cultura contemporânea/UFMT. Universidade Federal de Mato Grosso - Cuiabá- MT. https://orcid.org/0000-0003-2071-3967

Maria Lívia do Nascimento (mlivianascimento@gmail.com)

Doutora em Psicologia/PUC-SP. Professora titular de psicologia/UFF. Niterói-RJ. https://orcid.org/0000-0002-6451-484X

Luanna Tomaz (luannatomaz@hotmail.com)

Professora doutora em direito/UFPA.Belém-PA. https://orcid.org/0000-0002-8385-8859 unrestricted use, distribution and reproduction in any medium, provided the original article is properly cited. 